pp. 1-11. In The evidence of health promotion effectiveness: Shaping public health in a new Europe. International Union for Health Promotion and Education, Brussels.

Outhwaite W 1987. New philosophies of social science: realism, hermeneutics and critical theory. MacMillan, London.

Pawson R 2001. Evidence and policy and naming and shaming. ESRC UK Centre for Evidence Based Policy and Practice.

Pawson R 2002. Evidence-based policy: In search of a method. Evaluation 8(2):157-181.

Pawson R 2002. Evidence-based policy: The promise of "realist synthesis". Evaluation 8(3):340-358.

Pawson R 2003. Nothing as practical as a good theory. Evaluation 9(4):471-490.

Pawson R 2003. Social care knowledge: Seeing the wood for the trees. London, ESRC UK Centre for Evidence Based Policy and Practice: 1-23.

Pawson RC et al. 2003. Types and quality of social care knowledge - stage one: A classification of types of social care knowledge. London, ESRC UK Centre for Evidence Based Policy and Practice: 1-16.

Pawson R \& N Tilley 2001. Realistic evaluation bloodlines. American Journal of_Evaluation 22(3):317-324.

Potvin L et al. (2003). Implementing participatory intervention and research in communities: lessons from the Kahnawake Schools Diabetes Prevention Project in Canada. Social Science \& Medicine 56:1295-1305.

Potvin L et al. 2001. Beyond process and outcome evaluation: A comprehensive approach for evaluating health promotion programmes, pp. 45-62. In I Rootman et al. Evaluation in health promotion: Principles and perspectives. World Health Organization, Denmark.

Potvin L \& L Richard 2001. Evaluating community health promotion programmes, pp. 142-165. In I Rootman et al. Evaluation in health promotion: Principles and perspectives. WHO Europe, Copenhagen.

Sayer A 1992. Method in social science: A realist approach. Routledge, London-New York.

\section{Health Promotion and the Unified National Health System in Brazil: a necessary conceptual alignment} Promoção da Saúde e o Sistema Nacional de Saúde no Brasil: um alinhamento conceitual necessário

\section{Luiz Odorico Monteiro de Andrade 1 \\ Ivana Cristina de H. C. Barreto 2}

Antônio Ivo Carvalho and collaborators have produced an excellent paper on the importance of Health Promotion (HP) in the context of public policies and the need to monitor and evaluate HP policies and programs in order to help improve activities in this field.

The authors' paper has come at a prime moment for contributing to the conceptual alignment of the term Health Promotion. Here, we wish to highlight that the HP concept adopted by the authors was that of $a$ set of reflections and practices committed to surmounting the biomedical model, beginning with the positive and expanded concept of health, and taking the social process of its production as the focus.

The article comes at a time when a conceptual alignment is needed among institutional stakeholders in the Unified National Health System in relation to the Health Promotion strategy. This dilemma is at the very roots of our field. According to Article 196 of the 1988 Brazilian Constitution and Act 8.080/90, articles 2 and 3, the concept of Health Promotion appears as a synonym of a type of health action, which has led to a certain conceptual clash. An example of this conflict is where Article 196, which provides that health is the right of all and the duty of the state, guaranteed by means of social and economic policies aimed at reducing diseases and injuries and through actions and services for promotion, prevention, and rehabilitation. As observed in the underlined section, this use of the term Health Promotion reduces its meaning to the notion of one among other types of health actions, and this understanding has become common among actors and institutions in the health field. Such a construction has undermined the power of the HP concept as intended by the authors.

\footnotetext{
1 Secretary of Social Development and Health, Sobral, Ceará State, and President of the National Council of Municipal Health Secretaries (CONASEMS).

2 Director of Teaching and Research, "Visconde de Sabóia" Family Health Training School, Sobral, Ceará.
} 
The source of this conceptual confusion in the term Health Promotion dates to the 1960s, when Leavell \& Clark (1976) defined HP as "one of the five levels of prevention", thereby reducing the scope originally intended by Henry Sigerist (1996).

It is important to highlight that HP does still not constitute a new paradigm from the Kuhnian (1995) point of view, but represents a paradigmatic tension for the hegemonic biomedical model that held sway throughout the $20^{\text {th }}$ century.

To illustrate this argument, we can turn to a three-dimensional geometric figure formed by three axes that move along the time line and according to the predominance of one of its vectors. The three axes are: political-operationalnormative, discursive, and paradigmatic (Andrade \& Barreto, 2002). In this sense, to the extent that in the discursive axis the discourses and conceptual alignments are consolidated politically in an operational and normative way, they also exert a tension on the biomedical paradigm. An example in Brazil is the disarmament policy recently implemented by the Federal government. In this particular case, the impact from gunshot wounds could have led merely to the expansion of emergency care and trauma services in the country. Based on evidence that homicides involving firearms were the main cause of death among adolescents and young adults in the country and that this problem could not be solved merely by expanding health care services, rather that it required broader social measures (as contended by various members of the country's public health community, with particular reference to the extensive academic output by Professor Maria Cecília Minayo, head of the Latin American Center on Violence at the Oswaldo Cruz Foundation), and backed by nongovernmental organizations, public administrators, legislators, and other social segments, the discussion was generated on the need to disarm Brazilian society. Such discourse, in turn, impacted the Executive and Legislative Branches and the drafting and enactment of the Disarmament Act.

This process led to a gain in the HP field in the political-normative-operational axis, legitimizing it in its formulation and consolidating it as a field of research, producing a paradigmatic tension in the axis of the biomedical model. (Figure 1)

Another important contribution by the article was that it retrieved the results of the review by Tounder in 1996 on studies concerning Health Education or Health Promotion initiatives catalogued by the UIPES (Union Interna-

Figure 1

Necessary changes in the axis of public health.

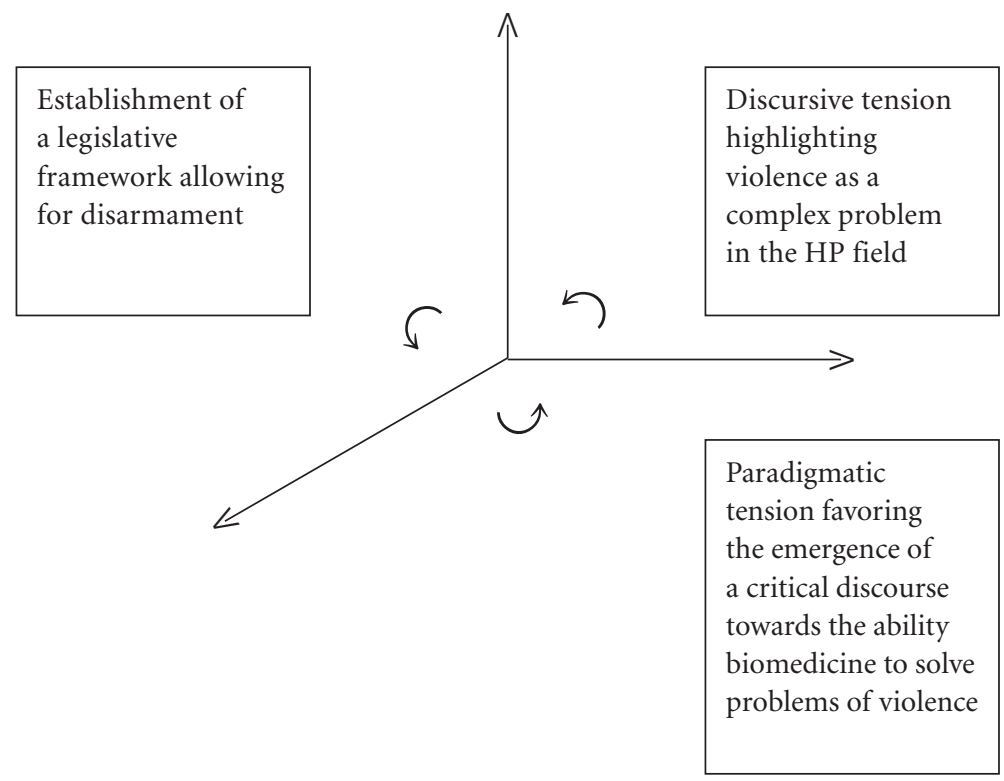


tionale de Promotion et d'Education pour la Santé), highlighting various contributions to improved quality of life for populations, including: a) progress in knowledge; b) mobilization of decision-makers for the definition or adjustment of the legislative framework; c) improvement in the state of health of certain populations, including reduced prevalence of certain diseases; and d) health cost containment.

The evaluation methods presented in the article appear to be consistent with HP, since they were not limited to quantitative studies. As highlighted by the authors, the latter are not sufficient for the analysis of complex experiences that are innovative in their interdisciplinarity and dialogue among various managers in the public administration, leading to inter-sectoral actions with integrated, participatory local development agendas.

The utilization of so-called "realist evaluation" for the study of HP policies, programs, and initiatives appears quite relevant, since it proposes the theories as the principal unit of analysis rather than the policies and programs themselves. According to the authors, the study of these theories is more effective for analyzing the potential generalization of the lessons learned.

At the end of the article, the reaffirmation of the need for "local understanding rather than universal truths" is in keeping with the current reality in the Brazilian health system, functioning in more than five thousand municipalities (or counties), with populations varying from fewer than five thousand to more than twelve million inhabitants. In this sense, the need for evaluation of local contexts for the improvement and adaptation of the HP strategy at the municipal level becomes imperative for the enhancement of public policies developed at the local level in Brazil.

\section{References}

Leavell HR \& Clark EG 1976. Medicina preventiva. Translated by Cecília F Donnangelo, Moises Goldbaum \& Uraci S Ramos. MacGraw-Hill do Brasil, São Paulo.

Sigerist HE 1996. Health. In HE Sigerist. Medicine and human welfare. Yale University Press. Reproduced in Journal of Public Health 17(2).

Kuhn TS 1995. A estrutura das revoluções científicas. Translated by por Beatriz Vianna Boeira \& Nelson Boeira. Editora Perspectiva, São Paulo.

Andrade LMO \& Barreto ICHC 2002. Promoção da saúde e cidades/municípios saudáveis: propostas de articulação entre saúde e ambiente, pp. 151-172. In MCS MCS \& AC Miranda. Saúde e ambiente sustentável: estreitando os nós. Fiocruz. Rio de Janeiro.

\section{The authors reply}

Os autores respondem

We wish to begin with special thanks to the colleagues who, on very short notice, commented so generously on this article, adding valuable contributions to the topic in debate and to the development of the Health Promotion field in Brazil. We would also like to publicly explain the reason for publishing this debate article in English: far from an attempt to smother "Latium's last flower" [the Portuguese language], as Fernando Cupertino so appropriately warned against, the article aims to foster a closer international dialogue which we intend to expand by sharing these reflections with participants of the 2nd International Conference on Local and Regional Health Programs: Strengthening the Integration of Promotion and Prevention in Health Systems, the theme of which highlights the relevance of this debate.

The HP field, as posited in the article and reaffirmed by the discussants, currently presents a conceptual and operational expansion of the overall health issue, wagering on a redesigning of practices and policies for the reduction of social inequality. An important clarification in relation to the issue raised by Márcia Westphal is that the challenge is to understand social-infrastructure, sanitation, and public health policies in general as "investments" rather than merely as social "expenditures"; therefore, the health sector and the population's health are viewed as a fundamental economic investment for human and social development. The HP field constitutes both a movement and privileged space for critique of the hegemonic biomedical model and prevailing health care practices within a new context of changes in public health (Kickbusch, 2004), where the influence and/or impact of services on health conditions is quite limited. The debate concerning HP actions and programs foster a sectoral agenda for the defense and preservation of health and quality of life against the logic of the market and profit, (re)introducing issues related to the excessive medicalization of practices and the necessary reorientation of health services and systems.

In the current context of globalization and growing complexity of societies as they relate to the need to reduce health inequalities, HP is consolidated through an interdisciplinary approach, inter-sectoral cooperation, and democ- 